\title{
Long-term survival after percutaneous irreversible electroporation of inoperable colorectal liver metastases
}

\author{
Andreas Schicho' \\ Christoph Niessen' \\ Michael Haimerl' \\ Isabel Wiesinger' \\ Christian Stroszczynski \\ Lukas P Beyer' \\ Philipp Wiggermann² \\ 'Department of Radiology, University \\ Hospital Regensburg, Regensburg, \\ Germany; ${ }^{2}$ Department of Radiology \\ and Nuclear Medicine, Klinikum \\ Braunschweig, Braunschweig, Germany
}

This article was published in the following Dove Medical Press journal: Cancer Management and Research

Background: For colorectal liver metastases (CRLM) that are not amenable to surgery or thermal ablation, irreversible electroporation (IRE) is a novel local treatment modality and additional option.

Methods: This study is a retrospective long-term follow-up of patients with CRLM who underwent IRE as salvage treatment.

Results: Of the 24 included patients, 18 (75.0\%) were male, and the median age was 57 (range: $28-75)$ years. The mean time elapsed from diagnosis to IRE was $37.9 \pm 37.3$ months. Mean overall survival was 26.5 months after IRE (range: 2.5-69.2 months) and 58.1 months after diagnosis (range: 14.8-180.1 months). One-, three-, and five-year survival rates after initial diagnosis were $100.0 \%, 79.2 \%$, and $41.2 \%$; after IRE, the respective survival rates were $79.1 \%, 25.0 \%$, and $8.3 \%$. There were no statistically significant differences detected in survival after IRE with respect to gender, age, T- or N-stage at the time of diagnosis, size of metastases subject to IRE, number of hepatic lesions, or time elapsed between IRE and diagnosis.

Conclusion: For nonresectable CRLM, long-term survival data emphasize the value of IRE as a new minimally invasive local therapeutic approach in multimodal palliative treatment, which is currently limited to systemic or regional therapies in this setting.

Keywords: liver metastases, survival, colorectal cancer, irreversible electroporation, long-term, salvage treatment, CRLM

\section{Introduction}

Colorectal cancer is the third most commonly diagnosed cancer in males and the second in females, with an estimated 1.4 million new cases and 693,000 deaths in 2012. The highest incidence rates are found in Australia, New Zealand, Europe, and Northern America. ${ }^{1}$ While incidence rates are rising, mortality rates in colorectal cancer are decreasing, most likely due to increased screening, reduced prevalence of risk factors, and improved treatments for early stage disease. ${ }^{2,3}$ In spite of these advancements, up to $80 \%$ of patients with colorectal liver metastases (CRLM) present with advanced stage disease at the time of diagnosis that is not amenable to surgery. ${ }^{4-7}$ In a setting of metastatic liver disease, minimally invasive therapies, such as irreversible electroporation (IRE), ${ }^{8,9}$ microwave ablation (MWA), radiofrequency ablation (RFA), or selective internal radiation therapy, are possible adjunct treatment options that can be performed after systemic or regional chemo- and immunotherapy. ${ }^{4}$ For patients with inoperable CRLM not suitable for thermal ablation techniques, IRE is a novel local treatment option in addition to chemo- and immunotherapies. ${ }^{10,11}$ IRE is a nonthermal ablation procedure still under early clinical investigation. ${ }^{12}$ In contrast to techniques using thermal ablation, the electrical field in
Correspondence: Andreas Schicho Department of Radiology, University Hospital Regensburg, Franz-Josef-StraußAllee II, D-93053 Regensburg, Germany Tel +49 94I 944 I 7409

Fax +49 94I 94417402

Email andreas.schicho@ukr.de 
IRE initially causes apoptosis instead of necrosis. Ultra-short high-voltage currents cause lethal pores in the cell membrane of tumor tissue, resulting in breakdown of the transmembrane potential $^{13}$ via creation of nanopores in the cell membrane. With subsequent influx and efflux of ions through the lipid bilayer, apoptosis, rather than necrosis, is induced, at least initially. ${ }^{14}$ This allows for ablation of metastases aligned with critical structures, such as vessels or adjacent organs. Data on patient survival after percutaneous IRE are scarce. ${ }^{9}$ Herein, we report the results of long-term follow-up of 24 patients with inoperable CRLM who underwent IRE.

\section{Materials and methods}

Twenty-four sequential patients with inoperable liver metastases from colorectal cancer treated with IRE (NanoKnife ${ }^{\circledR}$, Latham, NY, USA) before July 2015 were included in this retrospective long-term follow-up study. Initially, all cases were individually discussed in the interdisciplinary tumor board, and all physicians involved agreed on IRE treatment. Inclusion criteria were as follows: CRLM, age $>18$ years, informed consent, and ineligibility for thermal ablation or surgery. Exclusion criteria covered any contraindication for general anesthesia, cardiac pacemakers or ICD, vascular infiltration, CRLM with extrahepatic spread, preexisting cardiac conditions such as arrhythmias or significant heart failure, and severe coagulopathies. The University of Regensburg Institutional Review Board waived approval for this study due to the retrospective and fully anonymized character. All patient data were kept strictly confidential, and all requirements of the Declaration of Helsinki were fulfilled. In accordance with international, national, and local requirements, all patients provided written consent prior to IRE treatment. ${ }^{15,16}$ All IRE procedures were performed under general anesthesia and as described previously. ${ }^{17}$ Follow-up imaging (MRI of the liver using a liver-specific contrast agent [Gd-EOB-DTPA]) was acquired 6 weeks post-IRE, quarterly for 2 years, and semi-annually thereafter.

Kaplan-Meier survival curves were calculated and plotted using GraphPad Prism version 5.00a for Mac (GraphPad Software, San Diego, CA, USA). Log-rank statistics were calculated to identify factors of prognostic value for survival after either diagnosis or first IRE. Investigated variables included TNM tumor (T)/lymph node $(\mathrm{N}) /$ distant metastases (M) characteristics on diagnosis, gender, short axis diameter of IRE-treated lesions, and number of hepatic metastases. Age (young/old) and time of IRE (early/late) were grouped by the median cutoff. Survival was defined as either the time from diagnosis or the time from first IRE to death from any cause. Patients alive at the date last known were censored.
A value of $P<0.05$ for alpha was considered a statistically significant difference. For anonymized retrospective analyses, approval from the institutional ethics committee was waived.

\section{Results}

We included 24 patients with inoperable CRLM and IRE in our long-term follow-up study. Eighteen (75.0\%) were male, and the median age was 57 years, with a range of 28-75 years. Table 1 contains additional baseline characteristics.

At the time of diagnosis, $70.8 \%(n=17)$ of patients had stage T3 or T4 tumors, $66.7 \%(n=16)$ had lymph node metastases (N1 or N2), and 87.5\% $(n=21)$ had metastatic disease. Further baseline characteristics of the tumors are shown in Table 2. The mean time elapsed from diagnosis to IRE was $37.9 \pm 37.3$ months. Complete ablation was achieved in $16(66.7 \%)$ of 24 patients after the first IRE. With reintervention, complete ablation was achieved in 23 $(95.8 \%)$ of 24 patients.

Table I Baseline patient characteristics

\begin{tabular}{|l|l|}
\hline \multicolumn{2}{|l|}{ Characteristics } \\
\hline Female sex, $\mathrm{n}(\%)$ & $6(25.0)$ \\
\hline Age at Dx (years) & 57 \\
\hline Median & $28-75$ \\
\hline Range & 58.5 \\
\hline Age at IRE (years) & $31-80$ \\
\hline Median & $37.9 \pm 37.3$ \\
\hline Range
\end{tabular}

Abbreviations: $\mathrm{Dx}$, diagnosis; IRE, irreversible electroporation.

Table 2 Baseline tumor characteristics

\begin{tabular}{|c|c|}
\hline \multicolumn{2}{|l|}{ Characteristics } \\
\hline TNM staging, $\mathrm{n}(\%)$ & \\
\hline TI & $I(4.2)$ \\
\hline T2 & $5(20.8)$ \\
\hline T3 & $13(54.2)$ \\
\hline T4 & $4(16.7)$ \\
\hline No & $7(29.2)$ \\
\hline $\mathrm{NI}$ & $10(4 I .7)$ \\
\hline N2 & $6(25.0)$ \\
\hline MO & $2(8.3)$ \\
\hline MI & $21(87.5)$ \\
\hline \multicolumn{2}{|l|}{ Location, n (\%) } \\
\hline Colon ascendens & $4(16.7)^{b}$ \\
\hline Colon transversum & $2(8.3)$ \\
\hline Colon descendens & $0(0)$ \\
\hline Colon sigmoideum & $5(20.8)^{b}$ \\
\hline Rectum & $15(62.5)$ \\
\hline Hepatic metastases, $n \pm S D$, range, median & $2.0 \pm 1.9,1-9,2$ \\
\hline $\begin{array}{l}\text { Short axis diameter of IRE-treated hepatic } \\
\text { metastases, } \mathrm{cm} \pm \mathrm{SD} \text {, range, median }\end{array}$ & $2.3 \pm I .1,0.5-4.5,2$ \\
\hline
\end{tabular}

Note: ${ }^{\mathrm{M}}$ Missing data for one patient; ${ }^{\mathrm{b}}$ one case of simultaneous colon ascendens and colon sigmoideum.

Abbreviation: IRE, irreversible electroporation. 
There were no statistically significant differences between young vs old patients (median split; $\chi^{2}=1.335 ; P=0.25$; median: 23.9 vs 26.5 months; Figure $2 \mathrm{~B}$ ), female vs male patients $\left(\chi^{2}=1.302 ; P=0.25\right.$; median: 21.0 vs 26.5 months; Figure $2 \mathrm{~A}$ ), early vs late IRE (median split; $\chi^{2}=0.3908$; $P=0.53$; median: 26.1 vs 26.5 months; Figure $3 \mathrm{~B})$, one vs two or more hepatic metastases $\left(\chi^{2}=1.435 ; P=0.23\right.$; median: 24.6 vs 29.0 months; Figure 1C), small vs large ( $\geq 2 \mathrm{~cm})$ metastases subject to IRE treatment $\left(\chi^{2}=2.717 ; P=0.10\right.$; median: 32.0 vs
21.1 months; Figure 3A), initial tumor stage (T1/2 vs T3/4; $\chi^{2}=0.7287, P=0.39$; median: 34.5 vs 26.5 months; Figure $\left.1 \mathrm{~A}\right)$, or initial lymph node metastases (N0 vs N1 vs N2; $\chi^{2}=0.8407$, $P=0.66$; median: 16.6 vs 29.0 vs 26.7 months; Figure $1 \mathrm{~B}$ ).

Overall survival was 26.5 months after IRE (range: $2.5-69.2$ months) and 58.1 months after diagnosis (range: 14.8-180.1 months). One-, three-, and five-year survival rates after IRE were $79.1 \%, 25.0 \%$, and $8.3 \%$; the respective survival rates after initial diagnosis were $100.0 \%, 79.2 \%$, and $41.2 \%$ (Table 3 ).
A

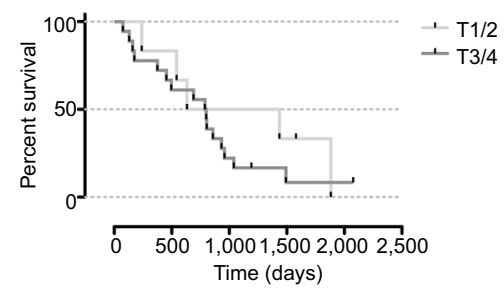

B

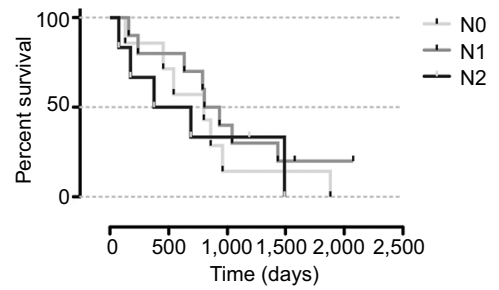

C

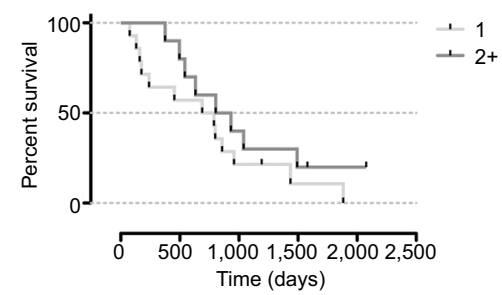

Figure I Kaplan-Meier survival curves based on tumor characteristics.

Notes: There were no statistically significant differences comparing T- and N-stage at the time of diagnosis or number of CRLM at the time of IRE. (A) TI/2 and T3/4. (B) $\mathrm{No}, \mathrm{NI}$, and N2. (C) One or more than one (2+) hepatic metastases.

Abbreviations: CRLM, colorectal liver metastases; IRE, irreversible electroporation.

A

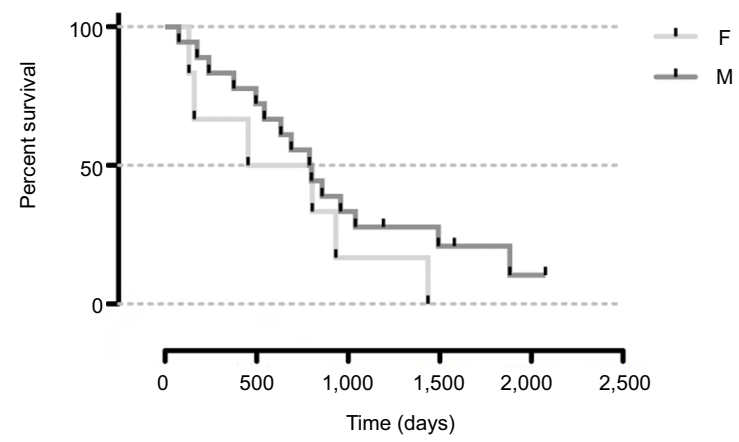

B

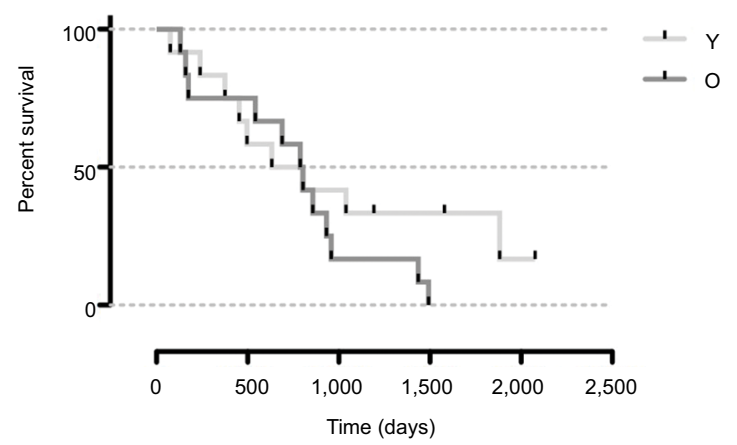

Figure 2 Kaplan-Meier survival curves based on patient characteristics.

Notes: No statistically significant difference was detected between gender and age. (A) Female (F) and male (M). (B) Young (Y) and old (O) patients, split by the median.

A

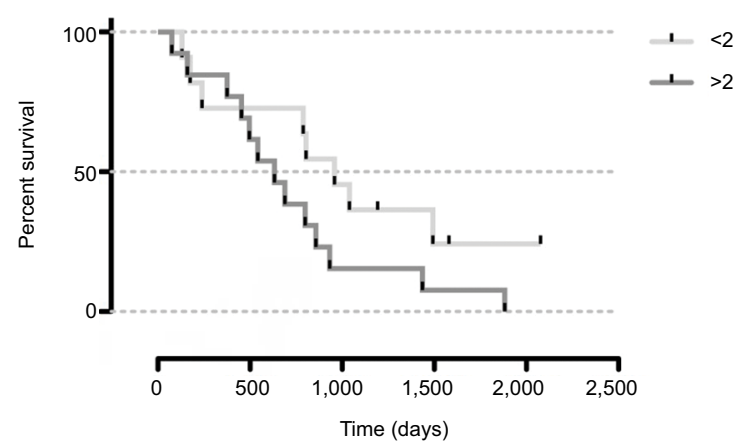

B

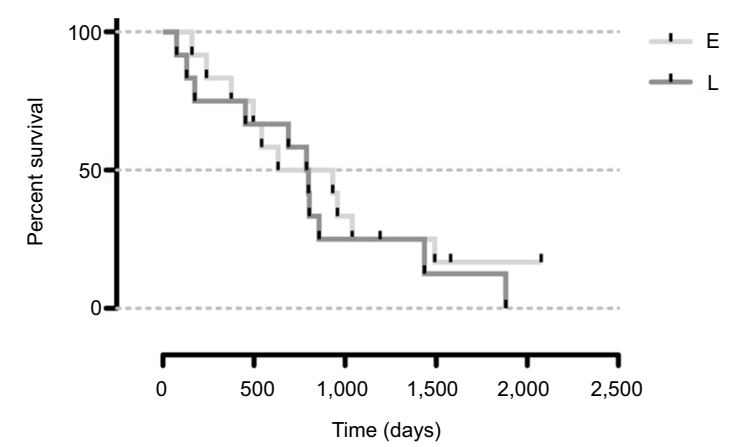

Figure 3 Kaplan-Meier survival curves based on IRE treatment characteristics.

Notes: Comparison of size of CRLM subjected to IRE and time of IRE after diagnosis, no statistically significant difference was found. (A) Size of the treated metastasis (smaller vs $\geq 2 \mathrm{~cm}$ ). (B) Early (E) or late (L) IRE, split by the median.

Abbreviations: CRLM, colorectal liver metastases; IRE, irreversible electroporation. 
Table 3 Survival after IRE

\begin{tabular}{|c|c|}
\hline \multicolumn{2}{|l|}{ Timespan } \\
\hline \multicolumn{2}{|c|}{ Survival after IRE (months) } \\
\hline Median & 26.5 \\
\hline Range & $2.5-69.2$ \\
\hline \multicolumn{2}{|c|}{ Survival after Dx (months) } \\
\hline Median & 58.1 \\
\hline Range & $|4.8-| 80 . \mid$ \\
\hline \multicolumn{2}{|c|}{ Survival after IRE, n (\%) } \\
\hline I year & $19(79.1)$ \\
\hline 2 years & $13(54.2)$ \\
\hline 3 years & $6(25.0)$ \\
\hline 4 years & $4(16.7)$ \\
\hline 5 years & $2(8.3)$ \\
\hline \multicolumn{2}{|c|}{ Survival after Dx, n (\%) } \\
\hline I year & $24(100.0)$ \\
\hline 2 years & $22(91.7)$ \\
\hline 3 years & $19(79.2)$ \\
\hline 4 years & $16(66.7)$ \\
\hline 5 years & $10(41.2)$ \\
\hline
\end{tabular}

Abbreviations: Dx, diagnosis; IRE, irreversible electroporation.

\section{Discussion}

Percutaneous ablation techniques have become a treatment option with several indications, including inoperable liver malignancies. While thermal ablation techniques, such as RFA or MWA, are limited by the so-called heat sink effect, nonthermal ablation with IRE is advantageous in the treatment of liver lesions adjacent to great vessels. IRE does not cause damage to intact adjacent structures, such as bile ducts, ${ }^{18}$ vessels, gall bladder, diaphragm, or heart, reducing the risk of complications. With advanced stage disease, patients in our cohort received IRE as a last treatment option. Since it is known that incomplete ablation of liver lesions causes decreased survival ${ }^{19}$ due to local recurrence ${ }^{20-22}$ and simultaneous tumor spread, ${ }^{23}$ IRE is very valuable for inoperable CRLM. ${ }^{24}$ In this palliative setting, our study was solely focused on survival, not covering local recurrence as primary or secondary end points. Ruers et al were the first to show that aggressive local treatment of CRLM, in addition to chemotherapy, prolongs overall survival. ${ }^{25}$

For hepatic metastases, IRE is the very last nonsystemic treatment option. It can even be suitable for lesions not amenable to surgery or thermal ablation. For CRLM, we observed a median survival of 26.6 months after the first IRE, which is markedly longer than that for the usual systemic treatment approaches alone. After completion of chemotherapy with fluorouracil and oxaliplatin, a median survival of 19.5 months has been reported, ${ }^{26}$ and for irinotecan, fluorouracil, and leucovorin, a median survival of 14.8 months was observed. ${ }^{27}$ Following chemotherapy with irinotecan and fluoropyrimidine, additional treatment with bevacizumab in combination with oxaliplatin, fluorouracil, and leucovorin conveyed an additional median survival of 12.9 months. ${ }^{28}$ From the time of diagnosis, our cohort reached a median survival of 58.1 months. Song et al compared MWA and resection of operable CRLM, not giving details on survival; however, an overall survival of little $>60$ months for MWA can be estimated. ${ }^{29}$

In our cohort, all patients were pretreated, and IRE was an additional therapeutic modality implemented in case with no alternative. The cases included in this cohort were not only inoperable but were also not amenable to thermal ablation. Thus, comparable data concerning survival benefits are very limited. van Iersel et al report a median survival of 25.0 months for isolated hepatic perfusion and 21.7 months for capecitabine, irinotecan, and oxaliplatin in isolated nonresectable CRLM. ${ }^{30}$ Solbiati et al report a 5-year survival of $47.8 \%$ for RFA added to systemic chemotherapy in patients not eligible for surgery or who refused surgery, compared to $41.2 \%$ in our cohort, ${ }^{31}$ comprised of patients who underwent various other therapies before IRE. For RFA as salvage therapy after hepatectomy, a 3-year survival of $41 \%$ was reported, compared to $25.0 \%$ (after IRE) and 79.2\% (after diagnosis) in our cohort. ${ }^{32}$

Due to the small cohort and retrospective study design, it is difficult to draw broad conclusions concerning the value of IRE in the treatment of secondary, inoperable liver malignancies. With a median survival longer than standard chemotherapy regimens, IRE should be regarded as the option-of-choice for patients with inoperable liver metastases who are not suitable for thermal ablation procedures. Further prospective randomized studies with a larger number of patients are needed to evaluate the value of IRE in the setting of CRLM. Moreover, detailed analysis of additional biomarkers, such as KRAS, ${ }^{33}$ as prognostic indicators is needed. ${ }^{34,35}$ In light of IRE being without an alternative in selected cases, ${ }^{17,36-38}$ a median survival of 26.6 months after first IRE is a promising result. Thus, we conclude that IRE is a valuable therapy for patients with CRLM not amenable to surgery or thermal ablation.

\section{Disclosure}

The authors report no conflicts of interest in this work.

\section{References}

1. Torre LA, Bray F, Siegel RL, Ferlay J, Lortet-Tieulent J, Jemal A. Global cancer statistics, 2012. CA Cancer J Clin. 2015;65(2):87-108.

2. Bosetti C, Levi F, Rosato V, et al. Recent trends in colorectal cancer mortality in Europe. Int J Cancer. 2011;129(1):180-191.

3. Edwards BK, Noone AM, Mariotto AB, et al. Annual report to the nation on the status of cancer, 1975-2010, featuring prevalence of comorbidity and impact on survival among persons with lung, colorectal, breast, or prostate cancer. Cancer. 2014;120(9):1290-1314. 
4. Prenen H, Van Cutsem E. Oncological management of unresectable liver metastases. Dig Dis. 2012;30(Suppl 2):137-142.

5. Manfredi S, Lepage C, Hatem C, Coatmeur O, Faivre J, Bouvier AM. Epidemiology and management of liver metastases from colorectal cancer. Ann Surg. 2006;244(2):254-259.

6. Gruber-Rouh T, Naguib NN, Eichler K, et al. Transarterial chemoembolization of unresectable systemic chemotherapy-refractory liver metastases from colorectal cancer: long-term results over a 10-year period. Int J Cancer. 2014;134(5):1225-1231.

7. Mattar RE, Al-Alem F, Simoneau E, Hassanain M. Preoperative selection of patients with colorectal cancer liver metastasis for hepatic resection. World J Gastroenterol. 2016;22(2):567-581.

8. Scheffer HJ, Nielsen K, van Tilborg AA, et al. Ablation of colorectal liver metastases by irreversible electroporation: results of the COLDFIRE-I ablate-and-resect study. Eur Radiol. 2014;24(10):2467-2475.

9. Scheffer HJ, Vroomen LG, Nielsen K, et al. Colorectal liver metastatic disease: efficacy of irreversible electroporation - a single-arm phase II clinical trial (COLDFIRE-2 trial. BMC Cancer. 2015;15(1):772.

10. Hosein PJ, Echenique A, Loaiza-Bonilla A, et al. Percutaneous irreversible electroporation for the treatment of colorectal cancer liver metastases with a proposal for a new response evaluation system. $J$ Vasc Interv Radiol. 2014;25(8):1233-1239.

11. Gonzalez-Beicos A, Venkat S, Songrug T, et al. Irreversible electroporation of hepatic and pancreatic malignancies: radiologic-pathologic correlation. Tech Vasc Interv Radiol. 2015;18(3):176-182.

12. Davalos RV, Mir IL, Rubinsky B. Tissue ablation with irreversible electroporation. Ann Biomed Eng. 2005;33(2):223-231.

13. Lee EW, Wong D, Prikhodko SV, et al. Electron microscopic demonstration and evaluation of irreversible electroporation-induced nanopores on hepatocyte membranes. J Vasc Interv Radiol. 2012;23(1): $107-113$.

14. Kim HB, Sung CK, Baik KY, et al. Changes of apoptosis in tumor tissues with time after irreversible electroporation. Biochem Biophys Res Commun. 2013;435(4):651-656.

15. Gillams A, Goldberg N, Ahmed M, et al. Thermal ablation of colorectal liver metastases: a position paper by an international panel of ablation experts, The Interventional Oncology Sans Frontières meeting 2013. Eur Radiol. 2015;25(12):3438-3454.

16. Ahmed M; Technology Assessment Committee of the Society of Interventional Radiology. Image-guided tumor ablation: standardization of terminology and reporting criteria - a 10-year update: supplement to the consensus document. JVasc Interv Radiol. 2014;25(11):1706-1708.

17. Niessen C, Thumann S, Beyer L, et al. Percutaneous irreversible electroporation: long-term survival analysis of 71 patients with inoperable malignant hepatic tumors. Sci Rep. 2017;7(1):43687.

18. Silk MT, Wimmer T, Lee KS, et al. Percutaneous ablation of peribiliary tumors with irreversible electroporation. J Vasc Interv Radiol. 2014;25(1):112-118.

19. Wang X, Sofocleous CT, Erinjeri JP, et al. Margin size is an independent predictor of local tumor progression after ablation of colon cancer liver metastases. Cardiovasc Intervent Radiol. 2013;36(1):166-175.

20. Shady W, Petre EN, Do KG, et al. Percutaneous microwave versus radiofrequency ablation of colorectal liver metastases: ablation with clear margins $(\mathrm{a} 0)$ provides the best local tumor control. J Vasc Interv Radiol. 2018;29(2):268-275.

21. Calandri M, Yamashita S, Gazzera C, et al. Ablation of colorectal liver metastasis: interaction of ablation margins and RAS mutation profiling on local tumour progression-free survival. Eur Radiol. 2018;28(7):2727-2734.
22. Shady W, Petre EN, Gonen M, et al. Percutaneous radiofrequency ablation of colorectal cancer liver metastases: factors affecting outcomes - a 10-year experience at a single center. Radiology. 2016;278(2): 601-611.

23. Lam VW, Ng KK, Chok KS, et al. Incomplete ablation after radiofrequency ablation of hepatocellular carcinoma: analysis of risk factors and prognostic factors. Ann Surg Oncol. 2008;15(3):782-790.

24. Lam VW, Spiro C, Laurence JM, et al. A systematic review of clinical response and survival outcomes of downsizing systemic chemotherapy and rescue liver surgery in patients with initially unresectable colorectal liver metastases. Ann Surg Oncol. 2012;19(4):1292-1301.

25. Ruers T, Van Coevorden F, Punt CJA, et al. Local treatment of unresectable colorectal liver metastases: results of a randomized phase II trial. J Natl Cancer Inst. 2017;109(9).

26. Goldberg RM, Sargent DJ, Morton RF, et al. A randomized controlled trial of fluorouracil plus leucovorin, irinotecan, and oxaliplatin combinations in patients with previously untreated metastatic colorectal cancer. J Clin Oncol. 2004;22(1):23-30.

27. Saltz LB, Cox JV, Blanke C, et al. Irinotecan plus fluorouracil and leucovorin for metastatic colorectal cancer. Irinotecan Study Group. $N$ Engl J Med. 2000;343(13):905-914.

28. Giantonio BJ, Catalano PJ, Meropol NJ, et al. Bevacizumab in combination with oxaliplatin, fluorouracil, and leucovorin (FOLFOX4) for previously treated metastatic colorectal cancer: results from the Eastern Cooperative Oncology Group Study E3200. J Clin Oncol. 2007;25(12):1539-1544.

29. Song P, Sheng L, Sun Y, An Y, Guo Y, Zhang Y. The clinical utility and outcomes of microwave ablation for colorectal cancer liver metastases. Oncotarget. 2017;8(31):51792-51799.

30. van Iersel LB, Koopman M, van de Velde CJ, et al. Management of isolated nonresectable liver metastases in colorectal cancer patients: a case-control study of isolated hepatic perfusion with melphalan versus systemic chemotherapy. Ann Oncol. 2010;21(8):1662-1667.

31. Solbiati L, Ahmed M, Cova L, Ierace T, Brioschi M, Goldberg SN. Small liver colorectal metastases treated with percutaneous radiofrequency ablation: local response rate and long-term survival with up to 10-year follow-up. Radiology. 2012;265(3):958-968.

32. Sofocleous CT, Petre EN, Gonen M, et al. CT-guided radiofrequency ablation as a salvage treatment of colorectal cancer hepatic metastases developing after hepatectomy. J Vasc Interv Radiol. 2011;22(6): 755-761.

33. Shady W, Petre EN, Vakiani E, et al. Kras mutation is a marker of worse oncologic outcomes after percutaneous radiofrequency ablation of colorectal liver metastases. Oncotarget. 2017;8(39):66117-66127.

34. Sofocleous CT, Garg S, Petrovic LM, et al. Ki-67 is a prognostic biomarker of survival after radiofrequency ablation of liver malignancies. Ann Surg Oncol. 2012;19(13):4262-4269.

35. Sotirchos VS, Petrovic LM, Gönen M, et al. Colorectal cancer liver metastases: biopsy of the ablation zone and margins can be used to predict oncologic outcome. Radiology. 2016;280(3):949-959.

36. Scaife CL, Curley SA. Complication, local recurrence, and survival rates after radiofrequency ablation for hepatic malignancies. Surg Oncol Clin NAm. 2003;12(1):243-255.

37. Curley SA, Izzo F, Delrio P, et al. Radiofrequency ablation of unresectable primary and metastatic hepatic malignancies: results in 123 patients. Ann Surg. 1999;230(1):1-8.

38. Shaw IM, Rees M, Welsh FKS, Bygrave S, John TG. Repeat hepatic resection for recurrent colorectal liver metastases is associated with favourable long-term survival. Br J Surg. 2006;93(4):457-464. 


\section{Publish your work in this journal}

Cancer Management and Research is an international, peer-reviewed open access journal focusing on cancer research and the optimal use of preventative and integrated treatment interventions to achieve improved outcomes, enhanced survival and quality of life for the cancer patient. The manuscript management system is completely online and includes a very quick and fair peer-review system, which is all easy to use. Visit http://www.dovepress.com/testimonials.php to read real quotes from published authors.

Submit your manuscript here: https://www.dovepress.com/cancer-management-and-research-journal 